\title{
Aprendendo com o insucesso: um estudo de caso de aplicação da resolução criativa de problemas ao projeto educativo
}

\author{
Learning from failure: A case study on the use \\ of creative problem solving with the \\ educational project
}

\author{
Fernando Cardoso de SOUSA \\ José Manuel Brito Pires BICA² \\ lleana Pardal MONTEIRO'
}

\begin{abstract}
Resumo
O Projeto Educativo, como instrumento fundamental para a autonomia das escolas, em Portugal, deve aglutinar as principais expectativas da comunidade escolar, implicando rigor na metodologia de investigação, utilizada para sua elaboração, e na implementação da mudança requerida. O presente artigo relata a forma como foi possível obter esses aspectos, numa escola secundária, ao longo de mais de um ano, por meio do uso do método de Resolução Criativa de Problemas, que envolveu toda a comunidade escolar. Conforme o planeamento definido, a elaboração do Projeto Educativo seguiu os passos de um trabalho de investigação e resultou num documento estratégico e operacional, sujeito, posteriormente, a várias tentativas de implementação que, no entanto, tiveram apenas sucesso relativo. A discussão das condições necessárias para que o documento final possa servir de base à implementação das políticas e ações definidas, o que simplificaria todo o esquema de funcionamento escolar, sob um prisma de gestão efetiva das organizações, é aqui iniciada e sugerida para futuras investigações.
\end{abstract}

Palavras-chave: Inovação organizacional; Instituições acadêmicas; Resolução de problemas.

\begin{abstract}
The Educational Project in Portugal, as a fundamental instrument for school autonomy, must concentrate the main expectations of the school community, involving rigor in the research methodology used for its elaboration and in the implementation of the changes required. This article reports how these aspects were achieved in a high school, using the Creative Problem Solving method and involving the whole school community, over more than one year. According to the established planning, the preparation of the Educational Project followed the steps of a research project, resulting in a strategic and operational document, which was subsequently subjected to various implementation attempts. However, the success was only relative. The discussion of the conditions necessary for the final document to

$\boldsymbol{\nabla} \mathbf{v} \boldsymbol{\nabla}$

1 Universidade do Algarve, Faculdade de Economia, Centro de Investigação do Espaço e das Organizações. Campus de Gambelas, Ed.2, Piso 1, 8005-139, Faro, Portugal. Correspondência para/Correspondence to: F.C. SOUSA. E-mail: <cardoso_sousa@hotmail.com>.

2 Instituto Superior Afonso III, Departamento de Ciências de Educação, Curso de Ciências do Desporte. Loulé, Portugal.
\end{abstract}


be the basis for the implementation of policies and actions, by simplifying the whole scheme of school functioning, from the perspective of the effective management of organizations, is initiated here and suggested for future investigations.

Keywords: Organizational innovation; Schools; Problem solving.

Uma vez que o Projeto Educativo (PE) é um dos instrumentos mais importantes da autonomia das escolas em Portugal, pretendeu-se conciliar saberes, vontades e poderes variados na sua elaboração por meio da utilização de uma metodologia especialmente vocacionada para problemas complexos - o método de Resolução Criativa de Problemas (Creative Problem Solving - CPS). A utilização desse método permitiu trabalhar com uma equipe que integrou toda a comunidade escolar, e desenhar um plano de ação que abordou o PE como um projeto de investigação. A apresentação deste trabalho constitui a finalidade deste artigo, incluindo considerações sobre o PE e CPS, a investigação feita para a elaboração do PE, os resultados e algumas reflexões sobre os ensinamentos obtidos, em especial no que se refere à implementação das estratégias definidas no documento.

Este estudo seguiu todos os parâmetros éticos da pesquisa com seres humanos.

O Projeto Educativo é um documento de autonomia da escola, no qual deverão ser explicitados os princípios, os valores, as metas e as estratégias que a escola se propõe a cumprir Decreto-Lei nº 75 (Portugal, 2008). Ali devem residir a fonte de inspiração e as prioridades estratégicas das ações a desenvolver, e não o inverso, isto é, o documento só tem motivos de existência quando os atores escolares encontrarem razões para atuar, e não apenas para acrescentar sua elaboração como mais uma atividade escolar. O PE é ainda implicado no contexto da avaliação de desempenho dos professores Decreto regulamentar $n^{\circ} 2$ (Portugal, 2010), o que Ihe acrescenta importância uma vez que regula vários aspectos relativos a essa vertente.

Alguns estudos têm sido feitos no âmbito do PE. Costa (2008), por exemplo, analisou O PE como elemento que define a política de escola a fim de averiguar se as medidas tomadas pelo órgão

56 de gestão, sobre o insucesso escolar, tinham tido influência na construção do PE, em duas escolas do segundo e do terceiro ciclo do ensino básico (uma escola com mais sucesso e outra com níveis de insucesso mais elevado). Uma das principais conclusões remete para a possibilidade de, na escola com maior insucesso, existir uma inadequação entre política e realidade, dado que a primeira é orientada para o sucesso e as respetivas taxas de retenção (realidade) se interpretam como um indicador de menor eficácia. Também realçou que, apesar de em ambas as escolas ter sido concebido um conjunto diversificado de estratégias e ações, na escola com menor insucesso se verificou uma maior intencionalidade nas ações previstas, mediante um plano de atividades que indicava os objetivos de cada ação; na outra escola, não existiu muita clareza entre a estratégia e o objetivo que se pretendia alcançar ou o problema em que se pretendia atuar.

Correia (2007), ao analisar o papel dos departamentos curriculares na dinamização do trabalho colaborativo entre os professores, tendo como referência o PE da escola, concluiu haver a necessidade de reestruturação do modo de trabalho desses departamentos para ajudar os professores a envolverem-se em processos permanentes e contínuos de reflexão e de discussão em equipe. A criação de uma estrutura de trabalho flexível, intra e interdepartamentos, semelhante a um mosaico fluido, pode constituir uma oportunidade de os professores se envolverem em equipes que os ajudem na reflexão sobre a escola. A dinâmica dessa nova estrutura de trabalho depende da existência de um interesse comum, partilhado por todos, o que requer uma constante negociação de significados, objetivos e processos. A emergência de um novo estilo de liderança, capaz de fomentar a confiança, o envolvimento, a participação, o questionamento e a reflexão conjunta, é crucial para o desenvolvimento da colaboração entre os professores.

A adoção de um processo de trabalho em equipe pode contribuir para a prossecução desse 
objetivo, pelo que se apresentará um método que se tem revelado eficaz em diferentes situações e contextos.

\section{Resolução de problemas em grupo}

A integração da criatividade e da inovação, no nível grupal, pode ficar mais bem ilustrada nas metodologias de trabalho em grupo, visando a produção de ideias ou a resolução de problemas. Dentro dessa perspectiva, vários sistemas de trabalho criativo de grupo estão disponíveis desde que Alex Osborn (Osborn, 1953) apresentou o brainstorming como método de produção de ideias, e, mais tarde (Osborn, 1963), o método CPS. Da abordagem inicial do CPS, Basadur (1987; 1994) propôs um novo modelo, o Simplex Model, constituído por oito passos (encontrar o problema, analisar os fatos, definir o problema, encontrar as soluções, tomar a decisão, planejar a ação, planejar a aceitação e implementar a decisão).

Mediante o recurso a um método de trbalho, coordenado por uma liderança específica, consegue-se potenciar o desenvolvimento da imaginação (na fase divergente), o que permite, na fase convergente, escolher as melhores opções posteriormente. É um método dirigido à promoção da inovação através da valorização do conhecimento dos membros do grupo, numa sinergia dirigida para um objetivo da organização. Também permite implicá-los na decisão tomada e, assim, melhorar a ligação dos indivíduos à organização e ao projeto.

Sousa e Monteiro (2010), na sequência de uma série de aplicações no contexto empresarial português, reduziram o modelo de Basadur para cinco passos e, posteriormente, para quatro passos (Sousa, Pellissier, \& Monteiro, 2012). Num primeiro passo, a pré-consulta permite encontrar o objetivo; o segundo passo (definir o problema) e o terceiro (elaborar um plano de ação para resolver o problema) são realizados durante a reunião da equipe. Já a implementação da decisão (ação) está fora da reunião. A separação das fases de divergência e convergência só é clara na definição do problema: ambas estão mais interligadas durante a elaboração do plano de ação.

\section{A intervenção na escola secundária "X"}

A Escola $X$ iniciou suas atividades no ano letivo de 1994/1995. Situada na região portuguesa do Algarve, na zona norte de uma freguesia urbana e periférica, atualmente em crescimento, é frequentada por alunos, essencialmente oriundos dessa mesma zona, embora receba alguns alunos provenientes de outras freguesias do concelho, por razões de oferta curricular e atividades da escola, entre outras. No ano de 2009/2010, existiam 35 turmas, num total de 771 alunos, 109 professores e 46 não docentes.

A estrutura organizativa da escola rege-se pela legislação em vigor Decreto-Lei no 75 (Portugal, 2008): conselho geral, diretor, conselho pedagógico, conselho administrativo e outras estruturas educativas (departamentos curriculares e estruturas relacionadas às direções de turma).

O desenvolvimento deste projeto foi enquadrado numa ação de formação e apresentou etapas distintas. Numa primeira fase, foi realizada uma entrevista (a pré-consulta) entre a diretora da escola e o responsável pela aplicação do método, tendo sido definido o objetivo inicial - "Construir um PE para uma escola integradora".

Posteriormente, foi constituída uma equipe de trabalho, integrando, tal como recomenda Strauss (2002), os representantes das várias partes envolvidas: professores (Conselho Pedagógico), alunos (presidente da associação de alunos), pais (presidente da associação de pais) e representante dos funcionários.

Na primeira sessão, foram inventariados os fatos pertinentes para o objetivo inicial, tendo a equipe chegado à seguinte definição do problema: "Como poderíamos criar as condições para a participação da comunidade educativa?".

Na segunda sessão, os participantes definiram soluções para responder ao problema; dentre elas, o grupo escolheu "Criar uma identidade com os objetivos da escola". Finalmente, foram selecionadas tarefas no intuito de concretizar a solução 
encontrada: (1) Promover a integração de pais e alunos nas equipes pedagógicas existentes; (2) analisar a autoavaliação e a avaliação do PE anterior; (3) diagnosticar os problemas; (4) definir os objetivos; (5) avaliar a integração nas festas da escola.

Para cada tarefa foi identificado o "como" executar e vencer eventuais resistências, designada a subequipe responsável, a data-limite para a execução e a entidade avaliadora da qualidade de execução (ou o critério). No final da sessão, definiram-se a constituição e as tarefas da subequipe responsável pela comunicação interna, bem como a data da reunião de follow up do projeto.

\section{Execução do plano}

Na reformulação/elaboração do PE de escola, identificou-se a necessidade de construir um instrumento destinado a avaliar as perceções de alunos, professores, funcionários e encarregados de educação acerca dos problemas da escola. Como os instrumentos disponíveis faziam referência a aspetos obtidos através da teoria ou teorias mais ou menos consensuais no meio escolar e educativo, recorreu-se ao método das grades (Kelly, 1991) para conceber um questionário que considerasse as opiniões das pessoas na sua própria linguagem e, assim, ultrapassasse as dificuldades que advêm do fato de a maioria das pessoas atuarem de forma diferente daquela que afirmam.

Responderam ao questionário professores ( $n=63)$, alunos ( $n=373)$, funcionários ( $n=22)$, o que corresponde a $58 \%$ do total de professores e de funcionários, e a $48 \%$ dos alunos. A amostra foi de conveniência.

Foram ainda realizadas entrevistas, por alunos de Psicologia, com cada um dos elementos da equipe do PE (professores, alunos, funcionários e ?ᄁ encarregados de educação), com a seguinte per\% gunta: "Até que ponto a sua escola é uma escola integradora?". As respostas foram gravadas e transcritas, e o texto resultante foi submetido à análise de conteúdo e à análise fatorial de correspondências, via programa Data Mining (Lebart \&

58 Salem, 1994).
O tratamento do questionário evidenciou que os diferentes agentes escolares partilham uma perceção favorável da escola (sendo as médias globais todas superiores a 3). Contudo, os alunos apresentam uma média $(3,3)$ significativamente mais baixa $(p<0.01)$ do que os encarregados de educação, pais e professores (ambos com uma média de 3,6) e funcionários $(3,5)$.

As entrevistas foram submetidas à análise de conteúdo temática, tendo sido identificadas dez categorias, por sua vez submetidas à análise fatorial de correspondências, de modo a possibilitar sua representação gráfica.

A Figura 1 mostra as designações das categorias e, em números, os dez entrevistados (equipe do PE). Constata-se que o sistema de eixos organiza as categorias em torno dos polos negativo e positivo, na horizontal, e entre os agentes e a escola integradora, no eixo vertical. Verifica-se que a maior parte dos entrevistados reconhece a necessidade da estratégia positiva constituir o centro orientador de todas as atividades e considera, também, que o desenvolvimento deve centrar-se numa estratégia baseada tanto nos agentes (professores, alunos, funcionários e encarregados de educação) como nas ações de integração como um todo. Metade dos professores aparece do lado negativo, o que sugere a necessidade de concentrar sobre eles as soluções de transição para o lado positivo.

Como já referido, a intenção principal das entrevistas seria sua repetição, no final do projeto, para avaliar as diferenças de perceção resultantes da intervenção. Entretanto, isso não foi considerado de interesse, devido ao relativo insucesso da implementação.

\section{Follow up}

Na reunião de follow up, em 26 de maio de 2010, realizou-se uma síntese de todo o trabalho desenvolvido. Diante da necessidade de completar/ reformular as tarefas acordadas na segunda sessão, elaborou-se uma lista de fatos relativos à solução da sessão anterior, dando-lhe a forma de problema 


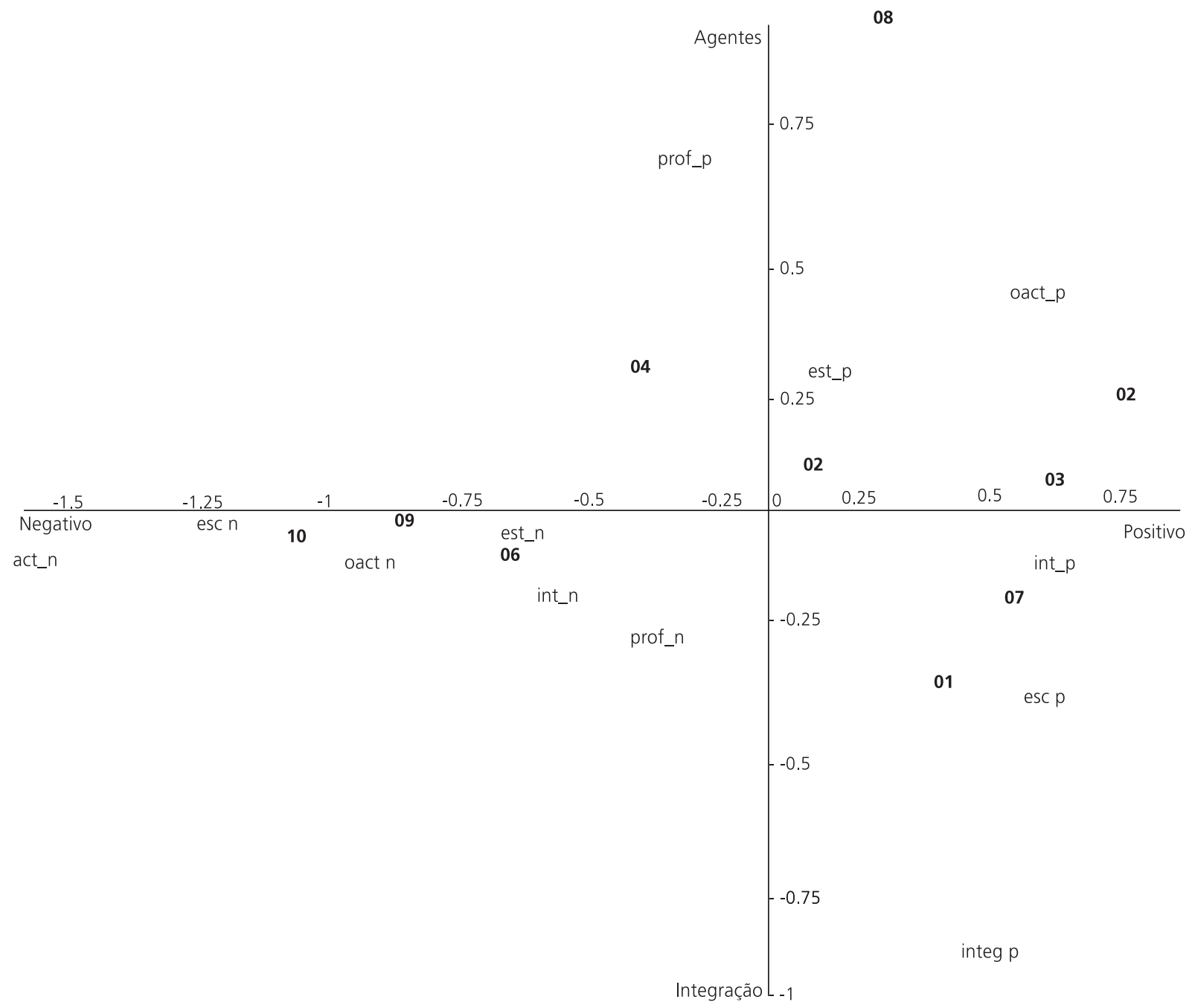

Figura 1. Análise fatorial de correspondências, mostrando a posição relativa das categorias de respostas diante da localização dos sujeitos entrevistados.

Nota: Legenda dos entrevistados: esc_p: escola positiva; est_p: estratégia positiva; int_p: integração positiva; oact_p: outros actores positivos; prof_p: professores positivo; esc_n - escola negativa; est_n - estratégia negativa; oact_n: outros actores negativos; prof_n: professores negativo; integ_p: integração passiva. Legenda das categorias dos estrevistados: Todos os valores se referem a professores entrevistados, excepto: 02: funcionário; 03: encarregado de educação; 08: aluno.

"Como poderíamos construir um PE para uma escola integradora?". Foram encontradas 30 considerações pertinentes, das quais foi selecionada uma, transformando-a em definição de problema: "Como levar a escola a apropriar-se do PE?".

Posteriormente, foram analisadas as resistências e as formas de as ultrapassar e, por fim, definidas as tarefas necessárias a fim de levar a escola a apropriar-se do PE. Foram identificadas as seguintes tarefas: (1) definir objetivos; (2) definir a avaliação do PE; (3) designar um grupo de acompanhamento; (4) operacionalização do PE.

\section{Aprovação e operacionalização do Projeto Educativo}

Na sequência dos procedimentos anteriormente referidos, a equipe responsável pela elaboração do PE finalizou a redação do documento, que, posteriormente, foi aprovado em conselho pedagógico de julho 2010.

Para operacionalizar o PE, a equipe de trabalho elencou e delimitou uma lista de problemas $(n=29)$, ou seja, desafios que, uma vez resolvidos, poderiam permitir atingir o objetivo inicial. Consen- 
sualmente, a equipe decidiu: "Quais os passos necessários para que a mudança possa ser levada a cabo pelas chefias intermédias?".

Na sequência, foi elaborado um plano de ação constituído por várias tarefas: (1) identificar a equipe do PE/criar um gabinete de apoio ao PE; (2) identificar chefias; (3) recolher feedback das chefias da escola; (4) elaborar FAQ (Frequently Asked Questions) e publicar, na página da escola, documentos orientadores para alunos e professores; (5) definir áreas de intervenção e (6) elaborar instrumentos de monitorização.

Todas as tarefas foram cumpridas, tendo sido criado um formulário digital de registo das atividades constantes no plano anual, o que facilitou, em teoria, a articulação com o PE.

A equipe de acompanhamento e monitorização do PE continuou, durante o ano escolar de 2011/2012, a produzir trabalho no âmbito da implementação do citado projeto. No entanto, a possibilidade de a escola entrar em agregação com outras, no ano escolar seguinte, veio colocar dúvidas quanto ao interesse em levar a diante um projeto que, em curto prazo, poderia estar ultrapassado.

A necessidade de clarificar os objetivos da equipe de acompanhamento promoveu uma nova intervenção para estruturar a execução do PE, em 25 de outubro de 2011. Da lista de problemas, a equipe de trabalho escolheu um "Quais os passos necessários para que o PE seja visto como documento orientador para a atividade da escola?".

As tarefas delineadas para sua resolução foram as seguintes: definir o âmbito de aplicação (consultar a direção e ver o impacto para os cursos regulares e profissionais; confirmar a escolha feita com os próprios); prever o impacto da reorganização (conversar com as escolas que já sofreram o processo de agrupamento e conhecer os projetos educativos das potenciais escolas que se vão agrupar com a nossa); mostrar as vantagens (aplicar a metodologia de CPS para produzir vantagens); prever o impacto sobre as estruturas escolares (aplicar CPS); fundir os objetivos pessoais com os do PE (aplicar (PS).

Ainda que tenham sido traçados objetivos a 60 alcançar e tarefas a realizar, não houve concertação, na interpretação de parte dos elementos da equipe, sobre o tratamento das tarefas designadas na sessão de CPS referida. Assim, a própria equipe acabou por não acreditar na possibilidade de sucesso da operacionalização do PE diante de alguma indiferença da direção e da incerteza do futuro da escola como unidade organizacional.

A equipe cessou funções em janeiro de 2012, por iniciativa própria. A entrega de um relatório à direção formalizou sua extinção.

\section{Discussão}

O desenvolvimento do PE apresentou etapas distintas, iniciadas ainda em 2010, com a pré-consulta à diretora da Escola, quando foi definido um objetivo inicial - a elaboração de um PE para uma escola integradora. Esse objetivo foi conseguido na sua totalidade e o método de resolução criativa de problemas revelou-se um processo adequado ao envolvimento da comunidade escolar na sua elaboração. Para além da estruturação da fase de arranque, crucial para o processo, o método serviu para fasear a execução do documento e organizar a participação da comunidade escolar através de questionários e entrevistas, na fase de diagnóstico.

Mais do que uma ferramenta para formação e treino de pensamento divergente, o CPS revelou-se uma forma rápida e eficaz de definir planos de ação, que, de outra forma, exigiriam maior tempo e discussões intermináveis. Pela via de inclusão dos vários agentes ligados à escola, permitiu-se fazer uma síntese de posições e opiniões muito diversas, chegando a soluções originais e úteis para os problemas definidos. De certa forma, tanto o método como o estilo de liderança facilitadora que Ihe está associado revelaram-se processos importantes para introduzir mudanças organizacionais.

Apesar das dificuldades existentes, foi possível concretizar, nos prazos estabelecidos, a realização de um documento estratégico e operacional, cuja construção foi abordada como se de um projeto de investigação se tratasse. Esse documento, pronto em 2010, foi reconhecido como importante, e, para sua execução, foram implementadas as três tenta- 
tivas relatadas, envolvendo outras tantas equipes ao longo do ano de 2011. Esses procedimentos, decorrentes da execução do PE, foram monitorizados por um observatório, criado para o efeito, com a finalidade de apresentar à direção um relatório a ser remetido ao conselho pedagógico, a quem compete deliberar acerca da correção dos fatos apresentados. Esse relatório do observatório e as deliberações do conselho pedagógico foram posteriormente enviados ao conselho geral.

Estava ainda previsto que o PE fosse avaliado anualmente (avaliação intermédia) e, no final do triênio 2010/2013 (avaliação final), pelas estruturas competentes. O PE deve ainda ser alvo de avaliação anual por parte do conselho pedagógico e do conselho geral, com a participação de toda a comunidade educativa, o que possibilita uma tomada de decisão mais fundamentada. Essas revisões anuais poderão ditar correções, prioridades e percursos que, em cada ano letivo, integrarão os planos de intervenção, plano anual de atividades e os projetos curriculares de escola e de turma.

Tudo está previsto para funcionar perfeitamente, mas, na prática e apesar de todos os procedimentos burocráticos existentes (que se supõe irão relatar uma execução satisfatória do PE), muito pouco do espírito presente no PE foi, ou se prevê que seja, levado à prática, em termos do desenvolvimento de uma verdadeira escola integradora, tal como ocorreu em circunstâncias idênticas, relatadas por outros investigadores (Costa, 2008; Correia, 2007). Embora pesem todas as tarefas ali previstas e respectivos indicadores que, potencialmente, acrescentam eficiência à organização, a maior parte dessas tarefas tinham a ver com ações que decorreriam mesmo sem PE e que pouco ou nada traduziam a visão integradora. Onde se encontram, então, as razões principais desse aparente insucesso em fazer executar um documento que preenche todos os requisitos para proporcionar uma mudança importante para a comunidade escolar, bem como em fazer com que uma estrutura organizativa complexa consiga essa tão desejada execução?

Não sendo objeto deste artigo dar uma resposta cabal a essas interrogações, não podem os seus autores deixar de refletir sobre as possíveis causas de uma tal situação:

a) A questão mais simples, quase ingênua, tem a ver com o fato de a generalidade dos profissionais não ver necessidade em avançar com mais medidas do que as regulamentares, pois é suposto ser assim que as coisas funcionam e, se tal não acontece, pouco ou nada mais se pode fazer. A própria equipe responsável pela construção do PE ficou algo surpreendida quando confrontada com a argumentação de que o trabalho apenas tinha sido iniciado e que o verdadeiro desafio estava em conseguir as mudanças definidas no documento, sobretudo no nível das atitudes favoráveis ao empenhamento num projeto coletivo. A própria direção manifestou a convicção de que nunca um PE terá sido implementado com esse grau de apuramento, pelo que exigir ainda mais não seria realista. No fundo, toda a intervenção foi vista, fundamentalmente, como se de uma ação de formação se tratasse e, portanto, não obrigatoriamente geradora de resultados para além da aprendizagem.

b) As implicações operacionais de um documento estratégico dessa natureza requerem um empenho decisivo e contínuo da direção, o que, no caso vertente, não chegou a existir. Apesar de a direção estar na origem do documento e de ter apoiado sua execução e difusão, a iniciativa não partiu dela, embora ela tenha proporcionado condições para se avançar para o passo seguinte. A direção não apoiou mais fortemente essa iniciativa talvez por não ter sido "conquistada", ou por estar consciente das dificuldades em gerar mudanças de atitude e das alterações constantes nas prioridades, que rapidamente passariam o PE para um plano secundário. Entretanto, os indicadores fundamentais relacionam-se mais com o número de candidaturas dos alunos, nada garantindo que uma boa execução do PE seja suscetível de melhorar esse indicador, pelo menos no curto prazo.

c) Os órgãos escolares, cuja missão consiste em secundar, avaliar e expandir a ação da direção, funcionam com dificuldade. Assim, existe uma multiplicidade de órgãos (ex: conselho de turma, conselho de diretores de turma, conselho de docentes, 
departamentos curriculares e grupos de docência), cuja missão expressa é a eficiência do funcionamento da escola, mas que, na prática, torna difícil a existência de qualquer ação coordenada.

d) Os documentos decorrentes do PE envolvem um volume de trabalho considerável e empenham muitos recursos na sua elaboração e avaliação sem, contudo, possuírem efeitos práticos no terreno. O sistema, devido a sua complexidade, torna-se perverso, levando a um sentimento individual de impotência.

e) Os organismos exteriores à escola, encarregados da avaliação, apesar de anunciarem uma orientação para os resultados, fazem incidir a maior parte da avaliação sobre os processos, nomeadamente os relativos ao cumprimento das normas legais da chamada autonomia da escola, como é o caso do PE. Essa visão paternalista da supervisão, ainda muito característica da relação entre as escolas e os organismos da tutela, acaba por ignorar os resultados efetivos do PE, apesar de poder reconhecer, em teoria, o valor do documento.

f) Os mecanismos que norteiam a avaliação de professores, se bem que prevejam uma parte dessa avaliação coincidente com o PE, ao não exigirem mais do que relatórios formais, sem inclusão de prova, acabam por não estabelecer qualquer contato com a realidade. A própria direção não está submetida a qualquer componente de avaliação por parte do Ministério da Educação e Ciência, indexado ao PE, e parte dos critérios de avaliação acaba por ser alheia ao desempenho, tal como evidenciado noutro trabalho (Bica \& Sousa, 2011). A pedra de toque da avaliação é a complexidade, a falta de transparência e a sobrecarga burocrática, na tentativa desesperada de encontrar a excelência quando, no fundo, apenas faz uma certificação sem significado real, que não enaltece ou apoia os bons professores, nem sanciona os maus. midor de recursos em práticas pouco produtivas de resultados, que todos parecem aceitar em detrimento da definição e resolução dos problemas reais da escola. A discussão esgota-se em torno dos temas já clássicos da centralização-descentralização, 62 estrutura organizativa e autonomia da escola, pres- supondo que serão as alterações estruturais e legislativas a ditar uma melhor eficiência e eficácia organizacionais sem, contudo, pôr em causa as razões das deficiências de funcionamento.

Do exposto se conclui pela necessidade de simplificar todo o esquema de funcionamento escolar, sob um prisma de gestão efetiva das organizações, libertando a instituição de uma série de obrigações burocráticas e estruturas com impacto negativo no que realmente interessa: a qualidade do ensino e da aprendizagem.

Relativamente à intervenção, embora pese o resultado favorável na elaboração de um documento com qualidade, admite-se que talvez tivesse havido excesso de ambição em querer obter uma mudança que não correspondia aos interesses e às possibilidades reais dos poderes instituídos, bem como à omissão de metas que melhor pudessem espelhar o cumprimento do PE. Mesmo a própria construção do PE deveria ter feito intervir um maior número de agentes (professores, alunos, funcionários e encarregados de educação), numa integração sucessiva de contribuições, devidamente sancionadas pela direção. A escolha não deveria ter recaído sobre as entidades representativas, mas sim sobre entidades operacionais que conhecessem profundamente os problemas, tivessem capacidade de os bloquear ou agilizar, ou que pudessem vir a ser afetadas pelas decisões, aumentando a participação da comunidade escolar.

Da mesma forma, querer limitar o PE a uma só escola é algo redutor, uma vez que o âmbito é demasiado restrito. O mais aceitável seria um alargamento, pelo menos às escolas secundárias do concelho, cujos diretores e entidades, exteriores à escola, pudessem colaborar desde o início e acompanhar a execução.

Apesar de todos esses fatores negativos e contrários a qualquer ação planejada, os autores deste trabalho são da opinião de que é possível aproximar mais as escolas dos padrões aceitáveis da eficácia organizacional, quanto mais não seja porque, felizmente, o universo escolar continua a dispor de vários exemplos de boas práticas de gestão (Bica, 2007) que podem servir de inspiração para a excelência. 
Tal como está, o PE não serve para muito, para além de manter o sistema do "faz de conta", e sua eliminação poderia facilitar a eliminação de estruturas e documentos sem impacto nos resultados finais da escola. Em sua substituição, o plano de atividades (plano de intervenção para o ano seguinte) serviria perfeitamente como base de planejamento de médio prazo. Se, tal como se pretende, a evolução for no sentido da verdadeira autonomização, então isso terá de corresponder, quer a um reforço da autoridade das chefias que, verdadeiramente, tornam-se necessárias a uma gestão efetiva da escola, quer a outra forma de intervenção dos encarregados de educação e demais entidades ligadas à escola. Nesse quadro de funcionamento, a metodologia ora empregada poderá ser uma boa ferramenta operacional, para além de constituir uma via importante para a aprendizagem de uma forma de liderança mais consentânea com o espírito da verdadeira autonomia das escolas.

O momento que o País atravessa justifica que se enfrentem os problemas reais e que se tente resolvê-los, simplificando processos e estruturas organizativas, avaliando os resultados e utilizando processos colaborativos que promovam um maior envolvimento da comunidade escolar, que ainda é aquela que, potencialmente, melhor pode conseguir constituir-se como exemplo a seguir por outras burocracias profissionais do Estado.

\section{Referências}

Basadur, M. (1987). Needed research in creativity for business and industrial applications. In S. G. Isaksen (Ed.), Frontiers of creativity research: Beyond the basics. Buffalo, NY: Bearly Limited.

Basadur, M. (1994). Simplex: A flight to creativity. Buffalo, N.Y.: The Creative Education Foundation.

Bica, J. (2007). Rankings y calidad educativa en los centros de enseñanza secundaria de el Algarve (Portugal) (Tese de doutorado não-publicada). Programa de Doutorado em Ciências da Educação, Universidade de Sevilha.

Bica, J., \& Sousa, F. (2011). Rankings e qualidade percebida nas escolas secundárias do Algarve. Revista Portuguesa de Pedagogia, 45(1), 93-109

Correia, A. (2007). Contributos do Projeto Educativo para o trabalho colaborativo e reflexivo entre os professores: um estudo de caso (Dissertação de mestrado não-publicada). Programa de Doutorado em Ciências da Educação, Universidade Aberta, Lisboa.

Costa, M. (2008). Política de escola e representações sore o insucesso escolar: um estudo de caso comparativo (Dissertação de mestrado não-publicada). Programa de Doutorado em Ciências do Comportamento, Instituto Universitário de Lisboa.

Portugal. Ministério da Educação. (2008, 11 de abril). Decreto-Lei $n^{\circ} 75$, de 22 de abril de 2008. Aprova o regime de autonomia, administração e gestão dos estabelecimentos públicos da educação pré-escolar e dos ensinos básico e secundário. Diário da República,

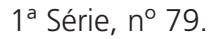

Portugal. Ministério da Educação. (2010, 14 de junho). Decreto regulamentar $n^{\circ} 2$, de 23 de junho de 2010. Estatuto da Carreira dos Educadores de Infância e dos Professores dos Ensinos Básico e Secundário. Diário da República, $1^{\text {a }}$ série, $\mathrm{n}^{\circ} 120$.

Kelly, G. (1991). A theory of personality, the psychology of personal constructs. New York: W. W. Norton.

Lebart, L., \& Salem, A. (1994). Statistique textuelle. Paris: Dunod.

Osborn, A. F. (1953). Applied imagination: Principles and procedures of creative problem-solving. New York: Scribner's Sons.

Osborn, A. F. (1963). Applied imagination: Principles and procedures of creative problem solving ( $3^{\text {rd }}$ rev. ed.). New York: Scribners.

Sousa, F., \& Monteiro, I. (2010). Liderança de equipas na resolução de problemas complexos: um guia para a inovação organizacional. Lisboa: Sílabo.

Sousa, F., Pellissier, R., \& Monteiro, I. (2012). Creativity, innovation and collaborative organizations. The International Journal of Organizational Innovation, 5(1), 1-39.

Strauss, D. (2002). How to make collaboration work. San Francisco: Berrett-Koehler.

Recebido em: 4/9/2012

Versão final em: 28/11/2012

Aprovado em: 30/1/2013 
